\title{
Effects of Ge Doping on the Charge Transport and Thermoelectric Properties of Permingeatites $\mathrm{Cu}_{3} \mathrm{Sb}_{1-y} \mathrm{Ge}_{y} \mathrm{Se}_{4}$
}

\author{
Ji-Hee Pi, Go-Eun Lee, and Il-Ho Kim* \\ Department of Materials Science and Engineering, Korea National University of Transportation, \\ Chungju 27469, Republic of Korea
}

\begin{abstract}
Permingeatites $\mathrm{Cu}_{3} \mathrm{Sb}_{1-y} \mathrm{Ge}_{y} \mathrm{Se}_{4}(0 \leq y \leq 0.14)$ were synthesized by mechanical alloying and hot pressing. The charge-transport parameters (Hall coefficient, carrier concentration, mobility, and Lorenz number) and thermoelectric properties (electrical conductivity, Seebeck coefficient, power factor, thermal conductivity, and figure of merit) were examined with respect to the Ge doping level. A single permingeatite phase with a tetragonal structure was obtained without subsequent heat treatment, but a small amount of the secondary phase $\mathrm{Cu}_{2} \mathrm{GeSe}_{3}$ was found for the specimens with $y \geq 0.08$. All hot-pressed compacts exhibited a relative density of $97.5 \%-98.3 \%$. The lattice constants of the $a$-axis and $c$-axis were decreased by the substitution of $\mathrm{Ge}$ at the $\mathrm{Sb}$ sites. As the Ge content increased, the carrier concentration increased from $5.2 \times 10^{18}$ to $1.1 \times 10^{20} \mathrm{~cm}^{-3}$, but the mobility decreased from 92 to $25 \mathrm{~cm}^{2} \cdot \mathrm{V}^{-1} \mathrm{~s}^{-1}$. The Lorenz number of the undoped $\mathrm{Cu}_{3} \mathrm{SbSe}_{4}$ implied a non-degenerate semiconductor behavior, ranging from (1.57-1.56) $\times 10^{-8} \mathrm{~V}^{2} \cdot \mathrm{K}^{-2}$ at $323-623 \mathrm{~K}$. The thermoelectric figure of merit was 0.39 at $623 \mathrm{~K}$, resulting from a power factor of $0.49 \mathrm{~mW} \cdot \mathrm{m}^{-1} \cdot \mathrm{K}^{-2}$ and a thermal conductivity of $0.76 \mathrm{~W} \cdot \mathrm{m}^{-1} \cdot \mathrm{K}^{-1}$. However, the Lorenz numbers of the Gedoped specimens indicated degenerate semiconductor characteristics, increasing to (1.63-1.94) $\times 10^{-8} \mathrm{~V}^{2} \cdot \mathrm{K}^{-2}$ at $323-623 \mathrm{~K}$. The highest thermoelectric figure of merit of 0.65 was at $623 \mathrm{~K}_{\text {for }} \mathrm{Cu}_{3} \mathrm{Sb}_{0.86} \mathrm{Ge}_{0.14} \mathrm{Se}_{4}$, resulting from the significantly improved power factor of $0.93 \mathrm{~mW} \cdot \mathrm{m}^{-1} \cdot \mathrm{K}^{-2}$ and the thermal conductivity of $0.89 \mathrm{~W} \cdot \mathrm{m}^{-1} \cdot \mathrm{K}^{-1}$. As a result, the thermoelectric properties were remarkably enhanced by doping Ge into the Sb sites of the permingeatite.
\end{abstract}

(Received March 23 2021; Accepted April 1, 2021)

Keywords: thermoelectric, charge transport, permingeatite, mechanical alloying, hot pressing

\section{Introduction}

Recently, thermoelectric materials composed of non-toxic, eco-friendly, low-cost, and earth-abundant elements have attracted attention, and $\mathrm{Cu}-\mathrm{Sb}$-Se ternary chalcogenides are among those materials considered to be promising candidates [1-3]. Among these, $\mathrm{Cu}_{3} \mathrm{SbSe}_{3}$ (bytizite) and $\mathrm{Cu}_{3} \mathrm{SbSe}_{4}$ (permingeatite) are expected to be superior thermoelectric materials because of their inherently low thermal conductivities. $\mathrm{Cu}_{3} \mathrm{SbSe}_{3}$ exhibits a low lattice thermal conductivity because of the lone-pair electrons of $\mathrm{Sb}^{3+}$, while $\mathrm{Cu}_{3} \mathrm{SbSe}_{4}$ has an unusually low lattice thermal conductivity without lone-pair electrons because the valence electrons of $\mathrm{Sb}^{5+}$ participate in

- 피지희·이고은: 박사과정, 김일호: 교수

*Corresponding Author: Il-Ho Kim

[Tel: +82-43-841-5387, E-mail: ihkim@ut.ac.kr]

Copyright (C) The Korean Institute of Metals and Materials bonding [4]. The electronic structure, thermal properties, phase diagram, and doping effects of $\mathrm{Cu}_{3} \mathrm{SbSe}_{4}$ were investigated by Wernick and Benson [5]. $\mathrm{Cu}_{3} \mathrm{SbSe}_{4}$ belongs to the space group $\mathrm{I} \overline{4} 2 \mathrm{~m}$ derived from the zinc-blende structure [6-8], and contains four times more atoms per unit cell than $\mathrm{ZnSe}$ [9]. The crystal structure of permingeatite comprises a three-dimensional $\mathrm{Cu}-\mathrm{Se}$ framework of distorted $\mathrm{CuSe}_{4}$ tetrahedrons and a one-dimensional $\mathrm{Sb}-\mathrm{Se}$ array of inserted $\mathrm{SbSe}_{4}$ tetrahedrons [7,8]. The $\mathrm{Sb}-\mathrm{Se}$ bonds are longer than the $\mathrm{Cu}-\mathrm{Se}$ bonds, and the $\mathrm{Cu}^{\mathrm{I}}-\mathrm{Se}$ bond lengths differ from those of $\mathrm{Cu}^{\mathrm{II}}-\mathrm{Se}$. These three bonding differences increase the anisotropy of charge transport and phonon scattering, which affect the electrical and thermal properties [8]. The permingeatite $\mathrm{Cu}_{3} \mathrm{SbSe}_{4}$ is a promising thermoelectric material because of its narrow direct bandgap (0.13-0.42 eV) and large carrier effective mass $\left(\sim 1.1 m_{\mathrm{o}}\right)$ [6,9]. However, 
further efforts are required to enhance $\mathrm{Cu}_{3} \mathrm{SbSe}_{4}$ thermoelectric performance because of its low power factor and thermoelectric figure of merit (ZT), resulting its low carrier concentration of (6$8) \times 10^{17} \mathrm{~cm}^{-3}[6,10]$. This can be accomplished by increasing the carrier concentration and thus electrical conductivity.

The effects of dopants on the thermoelectric properties of $\mathrm{Cu}_{3} \mathrm{SbSe}_{4}$ have been studied in efforts to improve them. Zhao et al. [11] reported a ZT of 0.54 at $650 \mathrm{~K}$ for $\mathrm{Cu}_{3} \mathrm{Sb}_{0.985} \mathrm{Ga}_{0.015}$ $\mathrm{Se}_{4}$, and Li et al. [12] obtained a ZT of 0.58 at $600 \mathrm{~K}$ for $\mathrm{Cu}_{3} \mathrm{Sb}_{0.97} \mathrm{Al}_{0.03} \mathrm{Se}_{4}$. Li et al. [13] reported a ZT of 0.70 at 600 $\mathrm{K}$ for $\mathrm{Cu}_{3} \mathrm{Sb}_{0.98} \mathrm{Bi}_{0.02} \mathrm{Se}_{4}$, and Wei et al. [14] achieved one of 0.70 at $673 \mathrm{~K}$ for $\mathrm{Cu}_{3} \mathrm{Sb}_{0.98} \mathrm{Sn}_{0.02} \mathrm{Se}_{4}$. The ionic radius of $\mathrm{Ge}^{4+}$ is similar to that of $\mathrm{Sb}^{5+}$, and Ge contains one fewer valence electrons than $\mathrm{Sb}$, suggesting that $\mathrm{Ge}$ is a great acceptor for $\mathrm{Cu}_{3} \mathrm{SbSe}_{4}$. Chang et al. [15] prepared $\mathrm{Cu}_{2.95} \mathrm{Sb}_{0.96} \mathrm{Ge}_{0.04} \mathrm{Se}_{4}$ by melting at $1123 \mathrm{~K}$ for several hours, annealing at $653 \mathrm{~K}$ for $40 \mathrm{~h}$, and spark plasma sintering (SPS); the material had a ZT of 0.70 at $640 \mathrm{~K}$. Skoug et al. [9] synthesized $\mathrm{Cu}_{3} \mathrm{Sb}_{0.98} \mathrm{Ge}_{0.02}$ $\mathrm{Se}_{4}$ by melting at $1173 \mathrm{~K}$ for $12 \mathrm{~h}$, annealing at $573 \mathrm{~K}$ for 48 $\mathrm{h}$, and hot pressing (HP), obtaining a ZT of 0.68 at $630 \mathrm{~K}$. In our previous study [16], we successfully synthesized $\mathrm{Cu}_{3} \mathrm{SbSe}_{4}$ via a solid-state route with mechanical alloying (MA; 350 rpm, $12 \mathrm{~h}$ ) and sintering by hot pressing (HP; $673 \mathrm{~K}, 2 \mathrm{~h}, 70$ $\mathrm{MPa}$ ). Although the $\mathrm{ZT}$ value of the undoped $\mathrm{Cu}_{3} \mathrm{SbSe}_{4}$ was only 0.39 at $623 \mathrm{~K}$, the thermoelectric performance may be enhanced by doping.

In this study, Ge-doped permingeatite $\mathrm{Cu}_{3} \mathrm{Sb}_{1-y} \mathrm{Ge}_{y} \mathrm{Se}_{4}(0 \leq$ $y \leq 0.14$ ) powders were synthesized by MA and consolidated by HP, and the effects of Ge doping on the charge-transport and thermoelectric properties were examined.

\section{Experimental Procedure}

To synthesize Ge-doped permingeatites $\mathrm{Cu}_{3} \mathrm{Sb}_{1-y} \mathrm{Ge}_{y} \mathrm{Se}_{4}(y$ $=0,0.04,0.08,0.12$, and 0.14$), \mathrm{Cu}(<45 \mu \mathrm{m}$, purity $99.9 \%$, Kojundo), Sb ( $<150 \mu \mathrm{m}$, purity $99.999 \%$, Kojundo), Ge ( $<45 \mu \mathrm{m}$, purity $99.99 \%$, Kojundo), and Se $(<10 \mu \mathrm{m}$, purity $99.9 \%$, Kojundo) powders were stoichiometrically weighed. The mixed powders were mechanically alloyed using a planetary ball mill (Fritsch, Pulverisette5) at $350 \mathrm{rpm}$ for 12 $\mathrm{h}$ in an Ar atmosphere. The synthetic permingeatite powders were sintered using HP with a graphite die with an inner diameter of $10 \mathrm{~mm}$ at $573 \mathrm{~K}$ for $2 \mathrm{~h}$ at $70 \mathrm{MPa}$. The detailed
MA-HP process for permingeatite was reported in our previous study [16]. The sintered compacts were cut into discs of $1 \mathrm{~mm}$ (thickness) $\times 10 \mathrm{~mm}$ (diameter) to measure the Hall coefficient and thermal diffusivity, and cut into parallelepipeds of $3 \mathrm{~mm} \times 3 \mathrm{~mm} \times 9 \mathrm{~mm}$ to measure electrical conductivity and Seebeck coefficient.

The phases were analyzed by X-ray diffraction (XRD; Bruker, D8-Advance) with $\mathrm{Cu} \mathrm{K} \alpha$ radiation $(40 \mathrm{kV}, 30 \mathrm{~mA})$. The diffraction angles were measured in the $2 \theta$ range $10-90^{\circ}$ with a scanning step of $0.02^{\circ}$ and a step duration of $0.4 \mathrm{~s}$. The lattice constants were calculated by Rietveld refinement using the TOPAS program. The microstructures of the hotpressed specimens were observed by scanning electron microscopy (SEM; FEI, Quanta400) in the backscattered electron (BSE) mode. Elemental line scans and maps were obtained by energy-dispersive spectrometry (EDS; Bruker, XFlash4010), employing the energy levels of the $\mathrm{Cu}$ K-series (8.046 eV), Sb L-series (3.604 eV), Ge K-series (9.886 eV), and Se K-series (11.224 eV). Charge-transport parameters were examined by measuring the Hall coefficient with a magnetic field (1 T) and electric current (100 mA DC) using the van der Pauw method (Keithley 7065). The thermoelectric properties were measured at temperatures of 323-623 K. The thermal conductivity was estimated from the thermal diffusivity, specific heat, and density using a TC-9000H (Advance Riko) system with the laser flash method in a vacuum. The Seebeck coefficient and electrical conductivity were measured using a ZEM-3 (Advance Riko) instrument with the four-probe method in a He atmosphere. The power factor and thermoelectric figure of merit ZT were also evaluated.

\section{Results and Discussion}

Figure 1 shows the XRD patterns of $\mathrm{Cu}_{3} \mathrm{Sb}_{1-y} \mathrm{Ge}_{y} \mathrm{Se}_{4}$ processed by MA-HP. The diffraction peaks matched the standard diffraction pattern (ICDD PDF\# 01-085-0003) for permingeatite and confirmed that the samples had tetragonal structures (space group $\mathrm{I} \overline{4} 2 \mathrm{~m}$ ). However, the secondary phase of $\mathrm{Cu}_{2} \mathrm{GeSe}_{3}$ was identified in the Ge-doped specimens with $y \geq 0.08$. The diffraction peaks were shifted to higher angles with increasing Ge content, indicating lattice shrinkage. The calculated lattice constants are listed in Table 1. The 
Table 1. Chemical compositions, relative densities, and lattice constants of $\mathrm{Cu}_{3} \mathrm{Sb}_{1-y} \mathrm{Ge}_{y} \mathrm{Se}_{4}$.

\begin{tabular}{|c|c|c|c|c|}
\hline \multicolumn{2}{|c|}{ Composition } & \multirow{2}{*}{$\begin{array}{c}\text { Relative } \\
\text { density [\%] }\end{array}$} & \multicolumn{2}{|c|}{ Lattice constant [nm] } \\
\hline Nominal & Actual & & a-axis & c-axis \\
\hline $\mathrm{Cu}_{3} \mathrm{SbSe}_{4}$ & $\mathrm{Cu}_{3.44} \mathrm{Sb}_{0.67} \mathrm{Se}_{3.89}$ & 98.1 & 0.56485 & 1.12471 \\
\hline $\mathrm{Cu}_{3} \mathrm{Sb}_{0.96} \mathrm{Ge}_{0.04} \mathrm{Se}_{4}$ & $\mathrm{Cu}_{3.11} \mathrm{Sb}_{0.97} \mathrm{Ge}_{0.04} \mathrm{Se}_{3.88}$ & 98.2 & 0.56477 & 1.12480 \\
\hline $\mathrm{Cu}_{3} \mathrm{Sb}_{0.92} \mathrm{Ge}_{0.08} \mathrm{Se}_{4}$ & $\mathrm{Cu}_{3.24} \mathrm{Sb}_{0.83} \mathrm{Ge}_{0.07} \mathrm{Se}_{3.86}$ & 98.2 & 0.56458 & 1.12466 \\
\hline $\mathrm{Cu}_{3} \mathrm{Sb}_{0.88} \mathrm{Ge}_{0.12} \mathrm{Se}_{4}$ & $\mathrm{Cu}_{3.22} \mathrm{Sb}_{0.84} \mathrm{Ge}_{0.11} \mathrm{Se}_{3.83}$ & 97.5 & 0.56446 & 1.12425 \\
\hline $\mathrm{Cu}_{3} \mathrm{Sb}_{0.86} \mathrm{Ge}_{0.14} \mathrm{Se}_{4}$ & $\mathrm{Cu}_{3.06} \mathrm{Sb}_{0.82} \mathrm{Ge}_{0.17} \mathrm{Se}_{3.96}$ & 98.3 & 0.56439 & 1.12422 \\
\hline
\end{tabular}

lattice constants of the $a$-axis and $c$-axis decreased with increasing Ge content from 0.56485 to $0.56439 \mathrm{~nm}$ and from 1.12471 to $1.12422 \mathrm{~nm}$, respectively. This confirmed that $\mathrm{Ge}$ was successfully substituted at the Sb sites. Chang et al. [15] reported that $\mathrm{Cu}_{2.95} \mathrm{Sb}_{1-y} \mathrm{Ge}_{y} \mathrm{Se}_{4} \quad(y=0-0.06)$ contained a single permingeatite phase without secondary phases, and that both the $a$-axis and $c$-axis decreased with increasing Ge content. The decreased lattice constants were attributed to the smaller ionic radius of $\mathrm{Ge}^{4+}(53 \mathrm{pm})$ [17] relative to that of $\mathrm{Sb}^{5+}(60 \mathrm{pm})[8]$.

Figure 2 shows the SEM images of the fractured surfaces of the $\mathrm{Cu}_{3} \mathrm{Sb}_{1-y} \mathrm{Ge}_{y} \mathrm{Se}_{4}$. The hot-pressed compacts showed relative densities of $97.5 \%-98.3 \%$ as shown in Table 1 ; the theoretical density of permingeatite is $5.82 \mathrm{~g} \cdot \mathrm{cm}^{-3}$ [18]. The microstructure did not significantly change with changes in Ge content, however, the secondary phase was observed for the specimens with $y \geq 0.08$.

Figure 3 shows the BSE-SEM micrographs and elemental analyses of $\mathrm{Cu}_{3} \mathrm{Sb}_{0.86} \mathrm{Ge}_{0.14} \mathrm{Se}_{4}$. The matrix phase (gray

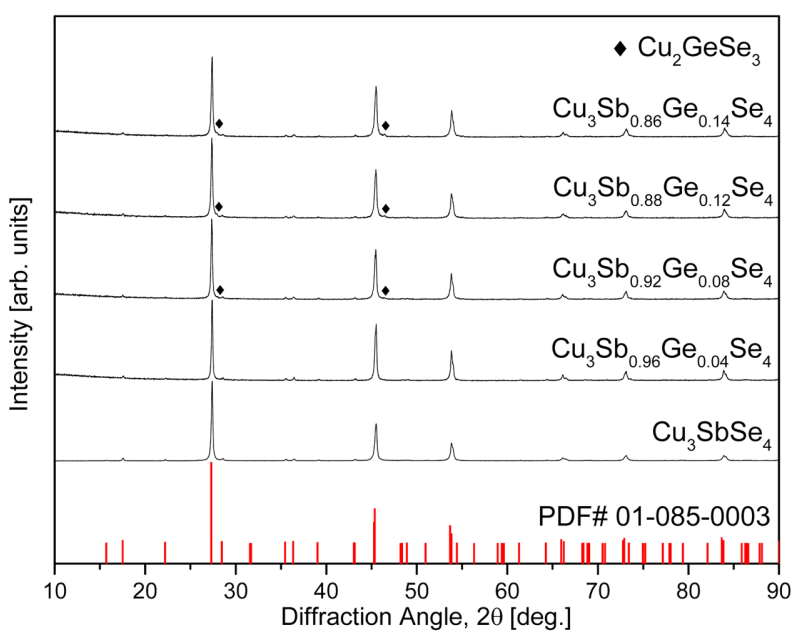

Fig. 1. XRD patterns of permingeatite $\mathrm{Cu}_{3} \mathrm{Sb}_{1-y} \mathrm{Ge}_{y} \mathrm{Se}_{4}$. region) and secondary phase (black region) were identified as permingeatite and $\mathrm{Cu}_{2} \mathrm{GeSe}_{3}$, respectively, which was confirmed by the XRD phase analysis (Fig. 1). The EDS elemental line scans and maps indicated that each constituent element was homogeneously distributed except in the secondary-phase areas. The actual compositions of all specimens, listed in Table 1, were similar to the nominal compositions within the analysis error range.

Figure 4 shows the carrier concentration and mobility of the $\mathrm{Cu}_{3} \mathrm{Sb}_{1-y} \mathrm{Ge}_{y} \mathrm{Se}_{4}$. The carrier concentration and mobility of undoped $\mathrm{Cu}_{3} \mathrm{SbSe}_{4}$ were $5.2 \times 10^{18} \mathrm{~cm}^{-3}$ and $50 \mathrm{~cm}^{2} \cdot \mathrm{V}^{-1} \cdot \mathrm{s}^{-1}$, respectively. As the $\mathrm{Ge}$ content increased, the carrier concentration increased to $(0.1-1.0) \times 10^{20} \mathrm{~cm}^{-3}$. However, the mobility rapidly decreased to $24 \mathrm{~cm}^{2} \cdot \mathrm{V}^{-1} \cdot \mathrm{s}^{-1}$ because of the significant increase in the carrier concentration of the specimen, with $y=0.14$. Chang et al. [15] reported an increase in carrier concentration from $8.0 \times 10^{18}$ to $3.2 \times 10^{20}$ $\mathrm{cm}^{-3}$ but a decrease in mobility from 76 to $21 \mathrm{~cm}^{2} \cdot \mathrm{V}^{-1} \cdot \mathrm{s}^{-1}$ for $\mathrm{Cu}_{2.95} \mathrm{Sb}_{1-y} \mathrm{Ge}_{y} \mathrm{Se}_{4}(y=0-0.06)$ with increasing Ge content. Brooks et al. [19] suggested that mobility generally decreases with increases in the carrier concentration in non-degenerate semiconductors. In this study, the carrier concentration and mobility increased with increasing Ge content, although the mobility decreased when $y>0.08$. This was because the Ge doping transforms the semiconducting state from nondegenerate to degenerate, and because the lattice distortion and ionized impurities enhanced the carrier scattering [14].

Figure 5 shows the electrical conductivity of $\mathrm{Cu}_{3} \mathrm{Sb}_{1-y} \mathrm{Ge}_{y}$ $\mathrm{Se}_{4}$. In the specimens with $y \leq 0.04$, the electrical conductivity increased slightly with increasing temperature, indicating non-degenerate semiconductor behavior. The electrical conductivity of the specimens with $y \geq 0.08$ decreased with increasing temperature, indicating degenerate semiconductor behavior. At a constant temperature, the electrical conductivity 


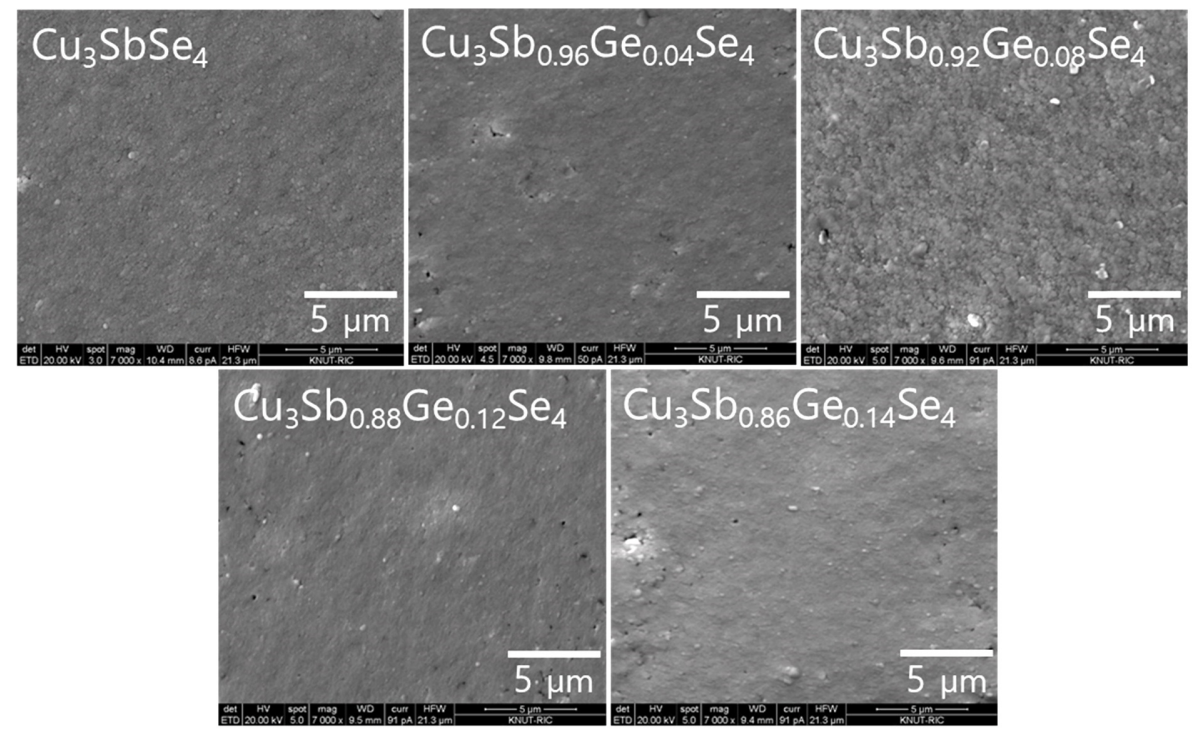

Fig. 2. SEM images of fractured surfaces for hot-pressed $\mathrm{Cu}_{3} \mathrm{Sb}_{1-y} \mathrm{Ge}_{\mathrm{y}} \mathrm{Se}_{4}$.

increased with $\mathrm{Ge}$ doping. For the undoped $\mathrm{Cu}_{3} \mathrm{SbSe}_{4}$, the electrical conductivity was $(4.2-4.5) \times 10^{3} \mathrm{~S} \cdot \mathrm{m}^{-1}$ at $323-623$ $\mathrm{K}$, whereas the Ge-doped specimens exhibited increased values of $(0.8-4.3) \times 10^{4} \mathrm{~S} \cdot \mathrm{m}^{-1}$ at $323 \mathrm{~K}$ and $(0.7-2.9) \times 10^{4}$ $\mathrm{S} \cdot \mathrm{m}^{-1}$ at $623 \mathrm{~K}$. Skoug et al. [9] reported that the electrical conductivity of $\mathrm{Cu}_{3} \mathrm{SbSe}_{4}$ showed a negative temperature dependence and a value of $(8.3-4.0) \times 10^{2} \mathrm{~S} \cdot \mathrm{m}^{-1}$ at $80-630$ $\mathrm{K}$, whereas that of $\mathrm{Cu}_{3} \mathrm{Sb}_{1-y} \mathrm{Ge}_{y} \mathrm{Se}_{4}(y=0.01-0.03)$ increased to $(0.3-1.1) \times 10^{4} \mathrm{~S} \cdot \mathrm{m}^{-1}$ at $80 \mathrm{~K}$ and $(1.3-4.0) \times 10^{3} \mathrm{~S} \cdot \mathrm{m}^{-1}$ at $630 \mathrm{~K}$ because the carrier concentration was increased to $10^{18}$ $10^{20} \mathrm{~cm}^{-3}$ by Ge doping. Chang et al. [15] obtained an electrical conductivity of $(1.0-1.1) \times 10^{3} \mathrm{~S} \cdot \mathrm{m}^{-1}$ at $300-640 \mathrm{~K}$ for $\mathrm{Cu}_{2.95} \mathrm{SbSe}_{4}$. However, the increased values of $(0.3-$ $1.1) \times 10^{4} \mathrm{~S} \cdot \mathrm{m}^{-1}$ at $300 \mathrm{~K}$ and $(1.7-5.6) \times 10^{4} \mathrm{~S} \cdot \mathrm{m}^{-1}$ at $623 \mathrm{~K}$ for $\mathrm{Cu}_{2.95} \mathrm{Sb}_{1-y} \mathrm{Ge}_{y} \mathrm{Se}_{4}(0.01 \leq y \leq 0.06)$ indicated a positive temperature dependence, which was attributed to the increase in carrier concentration from $8.0 \times 10^{18}$ to $3.2 \times 10^{19} \mathrm{~cm}^{-3}$ through Ge doping. In this study, the electrical conductivity was also increased by the increase in carrier concentration caused by Ge doping, as shown in Fig. 4, resulting from the additional carriers (holes) generated by $\mathrm{Ge}^{4+}$ substituted at the $\mathrm{Sb}^{5+}$ sites.

Figure 6 shows the Seebeck coefficients of $\mathrm{Cu}_{3} \mathrm{Sb}_{1-y} \mathrm{Ge}_{y}$ $\mathrm{Se}_{4}$. All specimens exhibited p-type conduction characteristics, and the majority carriers were holes, as confirmed by the positive signs of both the Seebeck coefficient and Hall coefficient. The Seebeck coefficient of $\mathrm{Cu}_{3} \mathrm{SbSe}_{4}$ increased from $307 \mu \mathrm{V} \cdot \mathrm{K}^{-1}$ at $323 \mathrm{~K}$ to $348 \mu \mathrm{V} \cdot \mathrm{K}^{-1}$ at $523 \mathrm{~K}$, and then

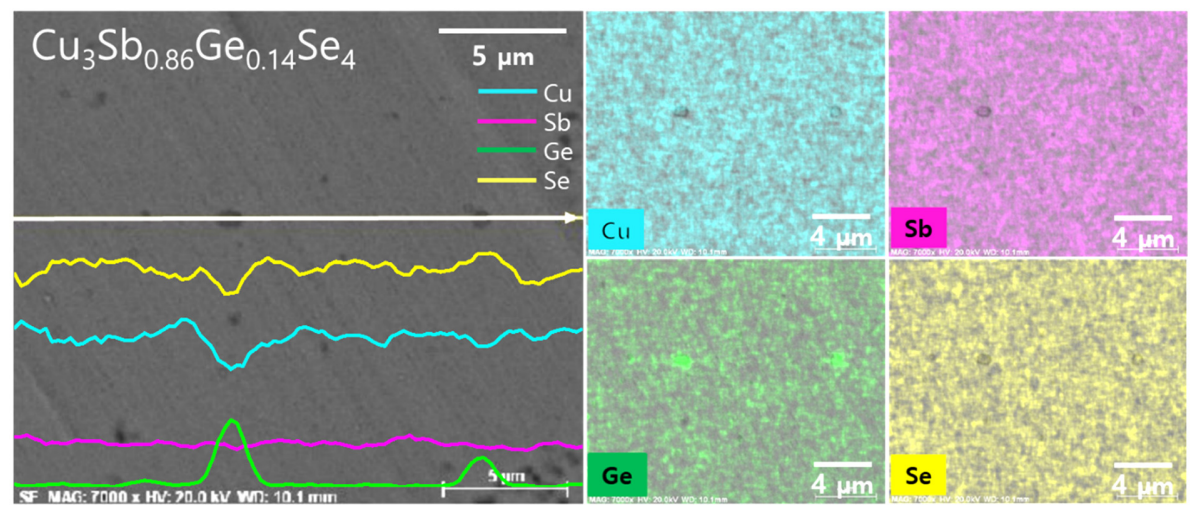

Fig. 3. BSE-SEM micrograph with EDS line scans and elemental maps of $\mathrm{Cu}_{3} \mathrm{Sb}_{0.84} \mathrm{Ge}_{0.14} \mathrm{Se}_{4}$. 


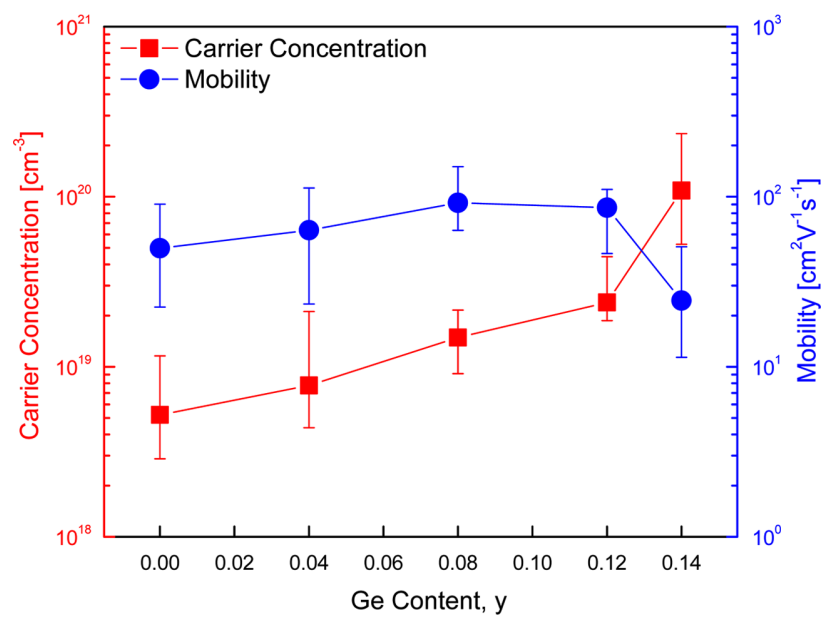

Fig. 4. Carrier concentration and mobility of $\mathrm{Cu}_{3} \mathrm{Sb}_{1-y} \mathrm{Ge}_{y} \mathrm{Se}_{4}$.

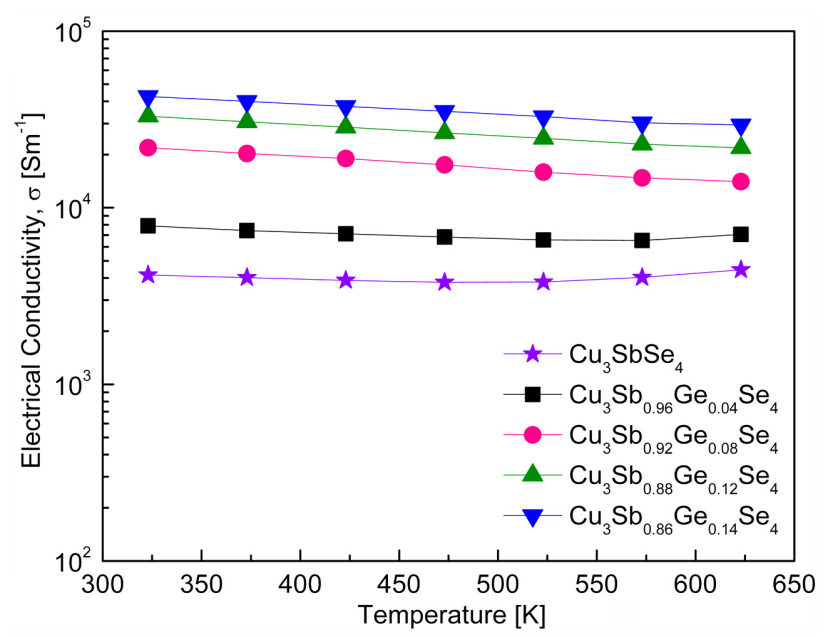

Fig. 5. Temperature dependence of the electrical conductivity for $\mathrm{Cu}_{3} \mathrm{Sb}_{1-\mathrm{y}} \mathrm{Ge}_{\mathrm{y}} \mathrm{Se}_{4}$.

decreased to $331 \mu \mathrm{V} \cdot \mathrm{K}^{-1}$ at $623 \mathrm{~K}$. Therefore, the Seebeck coefficient of undoped $\mathrm{Cu}_{3} \mathrm{SbSe}_{4}$ was decreased by the significant increase in carrier concentration, owing to the intrinsic transition at temperatures above $523 \mathrm{~K}$. However, for the specimen with $y=0.04$ the intrinsic transition occurred at temperatures above $573 \mathrm{~K}$, whereas it did not occur at temperatures up to $623 \mathrm{~K}$ for the specimens with $y \geq 0.08$. This implies that increases in the Ge doping level (carrier concentration) shifted the intrinsic transition to higher temperatures.

As the Ge content increased, the Seebeck coefficient decreased from 225 to $102 \mu \mathrm{V} \cdot \mathrm{K}^{-1}$ at $323 \mathrm{~K}$ and from 288 to $178 \mu \mathrm{V} \cdot \mathrm{K}^{-1}$ at $623 \mathrm{~K}$ due to the increase in carrier concentration.

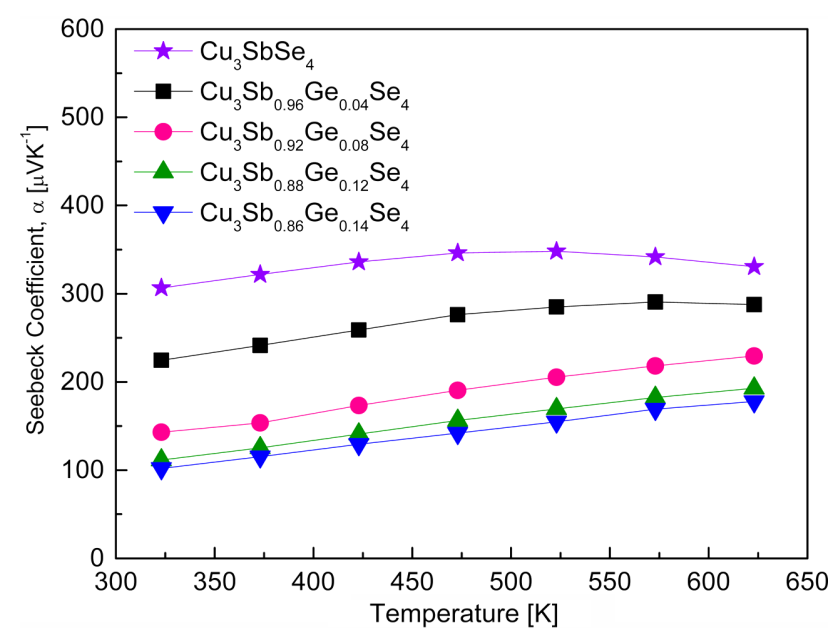

Fig. 6. Temperature dependence of the Seebeck coefficient for $\mathrm{Cu}_{3} \mathrm{Sb}_{1-\mathrm{y}} \mathrm{Ge}_{\mathrm{y}} \mathrm{Se}_{4}$.

Skoug et al. [9] reported that the Seebeck coefficient of $\mathrm{Cu}_{3} \mathrm{SbSe}_{4}$ reached $300-400 \mu \mathrm{V} \cdot \mathrm{K}^{-1}$ at $80-630 \mathrm{~K}$, with the maximum value at $320 \mathrm{~K}$. However, as the Ge content increased, the Seebeck coefficient of $\mathrm{Cu}_{3} \mathrm{Sb}_{1-y} \mathrm{Ge}_{y} \mathrm{Se}_{4}(y=$ $0.01-0.03$ ) decreased from 70 to $45 \mu \mathrm{V} \cdot \mathrm{K}^{-1}$ at $80 \mathrm{~K}$ and from 200 to $130 \mu \mathrm{V} \cdot \mathrm{K}^{-1}$ at $630 \mathrm{~K}$. Chang et al. [15] reported that the Seebeck coefficient of $\mathrm{Cu}_{2.95} \mathrm{SbSe}_{4}$ exhibited the highest value of $350 \mu \mathrm{V} \cdot \mathrm{K}^{-1}$ at $450 \mathrm{~K}$, and then decreased to 275 $\mu \mathrm{V} \cdot \mathrm{K}^{-1}$ at $640 \mathrm{~K}$ owing to the intrinsic transition of the material; however, the Seebeck coefficient of $\mathrm{Cu}_{2.95} \mathrm{Sb}_{1-y} \mathrm{Ge}_{y}$ $\mathrm{Se}_{4}(y=0.01-0.06)$ decreased to $160-69 \mu \mathrm{V} \cdot \mathrm{K}^{-1}$ at $300 \mathrm{~K}$ and $225-130 \mu \mathrm{V} \cdot \mathrm{K}^{-1}$ at $640 \mathrm{~K}$ because of the increase in carrier concentration by Ge doping.

Figure 7 shows the power factor of $\mathrm{Cu}_{3} \mathrm{Sb}_{1-y} \mathrm{Ge}_{y} \mathrm{Se}_{4}$. The power factor $\left(\mathrm{PF}=\alpha^{2} \sigma\right)$ is proportional to the Seebeck coefficient $(\alpha)$ and electrical conductivity $(\sigma)$; thus, it increases as the temperature increases due to the temperature dependences of the Seebeck coefficient and electrical conductivity. The power factor of $\mathrm{Cu}_{3} \mathrm{SbSe}_{4}$ was as low as $0.39-0.49 \mathrm{~mW} \cdot \mathrm{m}^{-1} \cdot \mathrm{K}^{-2}$ at $323-623 \mathrm{~K}$ with a small temperature dependence. However, as the Ge content increased, the power factor increased with a larger temperature dependence; $\mathrm{Cu}_{3} \mathrm{Sb}_{0.86} \mathrm{Ge}_{0.14} \mathrm{Se}_{4}$ exhibited the highest values of $0.44-0.93$ $\mathrm{mW} \cdot \mathrm{m}^{-1} \cdot \mathrm{K}^{-2}$ at $323-623 \mathrm{~K}$. The electrical conductivity and Seebeck coefficient have a trade-off relationship with the carrier concentration [20]. In this study, $\mathrm{Cu}_{3} \mathrm{Sb}_{0.86} \mathrm{Ge}_{0.14} \mathrm{Se}_{4}$ had the maximum power factor because it showed the highest 


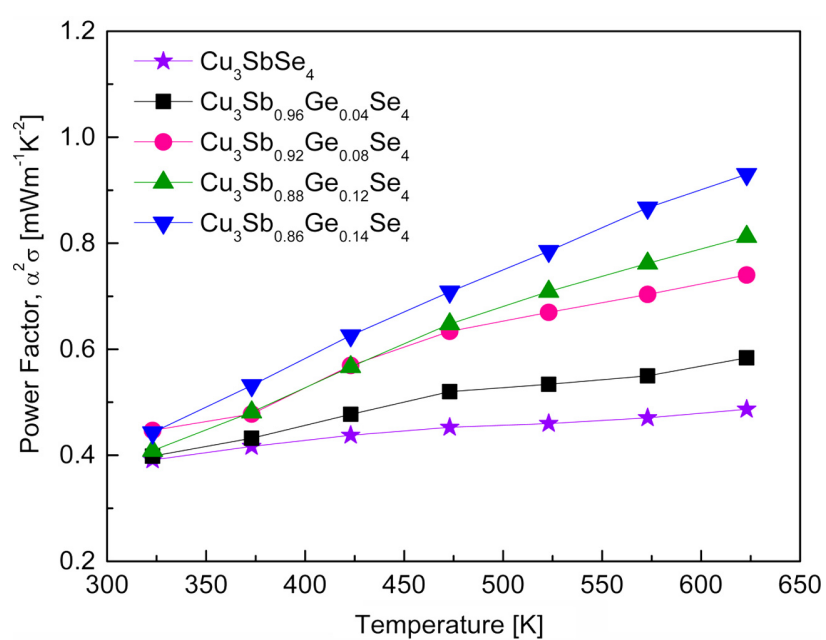

Fig. 7. Temperature dependence of the power factor for $\mathrm{Cu}_{3} \mathrm{Sb}_{1-}$ ${ }_{y} \mathrm{Ge}_{\mathrm{y}} \mathrm{Se}_{4}$.

electrical conductivity, despite also having the lowest Seebeck coefficient. Skoug et al. [9] reported the low power factor of $0.10-0.43 \mathrm{~mW} \cdot \mathrm{m}^{-1} \cdot \mathrm{K}^{-2}$ at $80-630 \mathrm{~K}$ for $\mathrm{Cu}_{3} \mathrm{SbSe}_{4}$, but higher values of $0.19-1.55 \mathrm{~mW} \cdot \mathrm{m}^{-1} \cdot \mathrm{K}^{-2}$ at $80-630 \mathrm{~K}$ for $\mathrm{Cu}_{3} \mathrm{Sb}_{1-y} \mathrm{Ge}_{y} \mathrm{Se}_{4}(y=0.02$ and 0.03$)$. Chang et al. [15] reported power factors of $0.81-1.15 \mathrm{~mW} \cdot \mathrm{m}^{-1} \cdot \mathrm{K}^{-2}$ at $300-640$ $\mathrm{K}$ for $\mathrm{Cu}_{2.95} \mathrm{SbSe}_{4}$ and $0.50-1.35 \mathrm{~mW} \cdot \mathrm{m}^{-1} \cdot \mathrm{K}^{-2}$ at $300-640 \mathrm{~K}$ for $\mathrm{Cu}_{2.95} \mathrm{Sb}_{1-y} \mathrm{Ge}_{y} \mathrm{Se}_{4}(y=0.01-0.06)$.

Figure 8 shows the thermal conductivity of the $\mathrm{Cu}_{3} \mathrm{Sb}_{1-y} \mathrm{Ge}_{y} \mathrm{Se}_{4}$. As shown in Fig. 8(a), the thermal conductivity decreased with increasing temperature. The thermal conductivity of undoped $\mathrm{Cu}_{3} \mathrm{SbSe}_{4}$ was 1.19-0.74 $\mathrm{W} \cdot \mathrm{m}^{-1} \cdot \mathrm{K}^{-1}$ at $323-623 \mathrm{~K}$, while Ge-doped specimens exhibited increased values of $1.27-1.36 \mathrm{~W} \cdot \mathrm{m}^{-1} \cdot \mathrm{K}^{-1}$ at $323 \mathrm{~K}$ and $\quad 0.76-0.89 \mathrm{~W} \cdot \mathrm{m}^{-1} \cdot \mathrm{K}^{-1}$ at $623 \mathrm{~K}$. The thermal conductivity $(\kappa)$ is expressed as $\kappa=D c_{p} d$, the product of the thermal diffusivity (D), specific heat $\left(c_{p}\right)$, and density (d). Therefore, the thermal conductivity is affected by the phases, compositions, and microstructures (grain boundaries, defects, pores, etc.), which depend on the preparation process. Skoug et al. [9] obtained the thermal conductivity of 15.0-1.0 $\mathrm{W} \cdot \mathrm{m}^{-1} \cdot \mathrm{K}^{-1}$ at $80-630 \mathrm{~K}$ for $\mathrm{Cu}_{3} \mathrm{Sb}_{1-y} \mathrm{Ge}_{y} \mathrm{Se}_{4}(y=0.02$ and 0.03 ) prepared by the melting-annealing and HP method. Chang et al. [15] reported a thermal conductivity of 2.98$1.25 \mathrm{~W} \cdot \mathrm{m}^{-1} \cdot \mathrm{K}^{-1}$ at $300-640 \mathrm{~K}$ for $\mathrm{Cu}_{2.95} \mathrm{Sn}_{y} \mathrm{Ge}_{1-y} \mathrm{Se}_{4}(y=0$ 0.06 ) fabricated by the melting-annealing and SPS methods. Compared with these reports, in this study, significantly
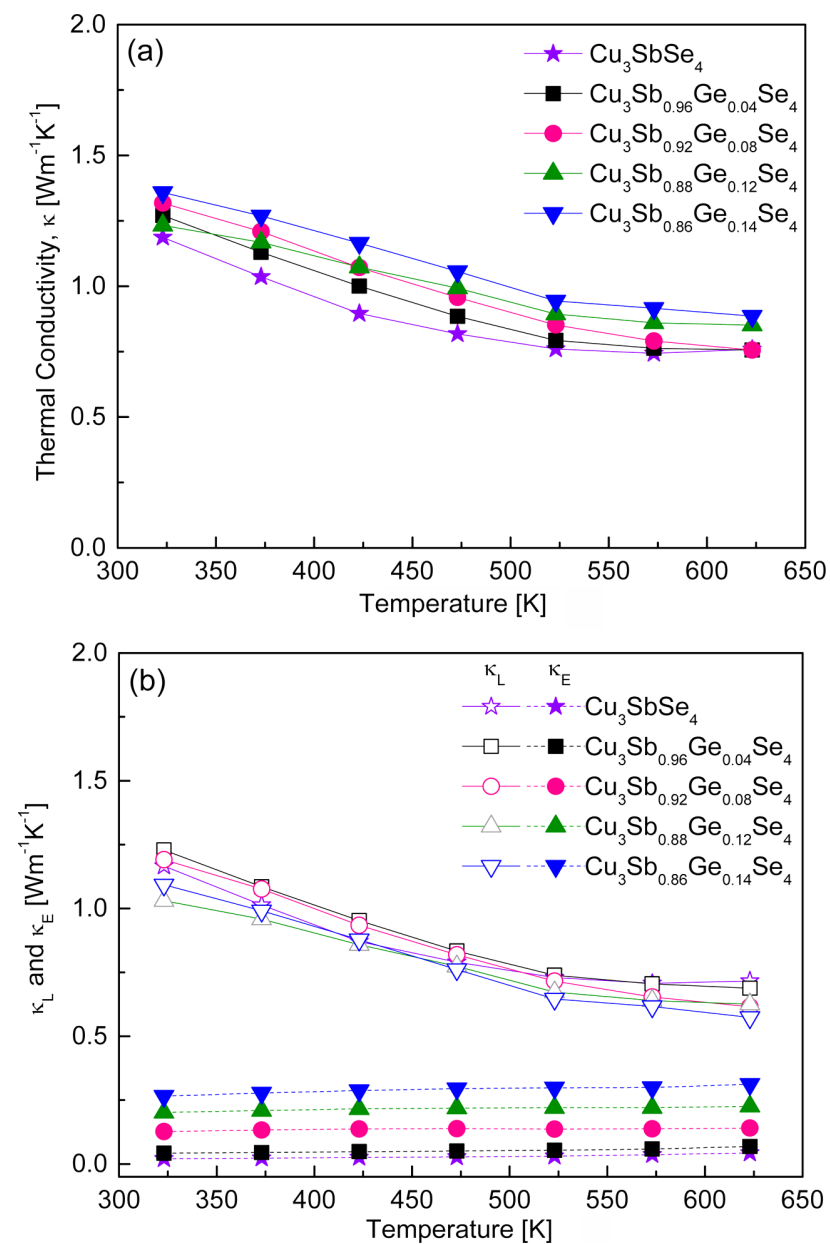

Fig. 8. Temperature dependence of the thermal conductivity for $\mathrm{Cu}_{3} \mathrm{Sb}_{1-\mathrm{y}} \mathrm{Ge}_{\mathrm{y}} \mathrm{Se}_{4}$ : (a) total thermal conductivity and (b) lattice and electronic thermal conductivities.

lower thermal conductivity values of $1.36-0.74 \mathrm{~W} \cdot \mathrm{m}^{-1} \cdot \mathrm{K}^{-1}$ were achieved at $323-623 \mathrm{~K}$ for $\mathrm{Cu}_{3} \mathrm{Sb}_{1-y} \mathrm{Ge}_{y} \mathrm{Se}_{4}(y=0.04-$ 0.14 ) by employing the MA-HP process.

The thermal conductivity is the sum of the lattice thermal conductivity $\left(\kappa_{\mathrm{L}}\right)$ and electronic thermal conductivity $\left(\kappa_{\mathrm{E}}\right)$, which are attributed to phonons and charge carriers, respectively [21]. Figure 8(b) shows the lattice and electronic thermal conductivities estimated using the WiedemannFranz law $\left(\kappa_{\mathrm{E}}=\mathrm{L} \sigma \mathrm{T}\right)$, where $\mathrm{L}$ is the temperature-dependent Lorenz number and $T$ is the absolute temperature [9]. The lattice thermal conductivity and electronic thermal conductivity of $\mathrm{Cu}_{3} \mathrm{SbSe}_{4}$ were $1.17-0.72 \mathrm{~W} \cdot \mathrm{m}^{-1} \cdot \mathrm{K}^{-1}$ and $0.02-0.04 \mathrm{~W} \cdot \mathrm{m}^{-1} \cdot \mathrm{K}^{-1}$ at $323-623 \mathrm{~K}$, respectively. The lattice thermal conductivity of Ge-doped specimens decreased to 


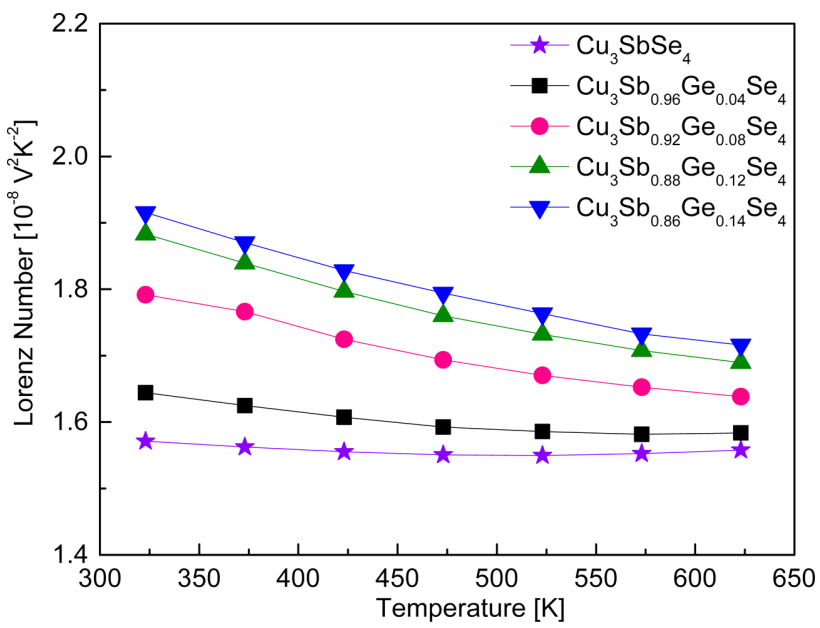

Fig. 9. Temperature dependence of the Lorenz number for $\mathrm{Cu}_{3} \mathrm{Sb}_{1-y}$ $\mathrm{Ge}_{\mathrm{y}} \mathrm{Se}_{4}$.

$1.23-1.09 \mathrm{~W} \cdot \mathrm{m}^{-1} \cdot \mathrm{K}^{-1}$ at $323 \mathrm{~K}$ and $0.72-0.57 \mathrm{~W} \cdot \mathrm{m}^{-1} \cdot \mathrm{K}^{-1}$ at $623 \mathrm{~K}$ because phonon scattering was enhanced by the ionized impurities and lattice distortions generated by $\mathrm{Ge}$ substitution at the $\mathrm{Sb}$ sites. However, the electronic thermal conductivity increased to $0.04-0.27 \mathrm{~W} \cdot \mathrm{m}^{-1} \cdot \mathrm{K}^{-1}$ at $323 \mathrm{~K}$ and $0.07-0.31 \mathrm{~W} \cdot \mathrm{m}^{-1} \cdot \mathrm{K}^{-1}$ at $623 \mathrm{~K}$ due to the increase in carrier concentration through $\mathrm{Ge}$ doping. As the $\mathrm{Ge}$ content increased, the lattice thermal conductivity decreased, while the electronic thermal conductivity increased. Therefore, the total thermal conductivity of $\mathrm{Cu}_{3} \mathrm{Sb}_{1-y} \mathrm{Ge}_{y} \mathrm{Se}_{4}$ was mainly determined by the lattice thermal conductivity, but the change in the total thermal conductivity was predominantly affected by the electronic thermal conductivity.

Figure 9 shows the Lorenz number of $\mathrm{Cu}_{3} \mathrm{Sb}_{1-y} \mathrm{Ge}_{y} \mathrm{Se}_{4}$. Theoretically, the Lorenz number is $(1.45-2.44) \times 10^{-8} \mathrm{~V}^{2} \cdot \mathrm{K}^{-2}$ [22]; smaller values indicate non-degenerate semiconductor behavior, while larger values indicate degenerate semiconductor or metallic conductor behavior. As shown in Fig. 8(b), the charge-carrier contribution to the thermal conductivity was determined using the Wiedemann-Franz law, and the Lorenz number was calculated using the equation [23]. In this study, the Lorenz number decreased with increasing temperature. The Lorenz numbers of undoped $\mathrm{Cu}_{3} \mathrm{SbSe}_{4}$ were low and constant between $1.57 \times 10^{-8}$ and $1.56 \times 10^{-8} \mathrm{~V}^{2} \cdot \mathrm{K}^{-2}$ at $323-$ $623 \mathrm{~K}$. However, the Lorenz number increased to (1.64-1.92) $\times 10^{-8} \mathrm{~V}^{2} \cdot \mathrm{K}^{-22}$ at $323 \mathrm{~K}$ and $(1.56-1.72) \times 10^{-8} \mathrm{~V}^{2} \cdot \mathrm{K}^{-2}$ at 623

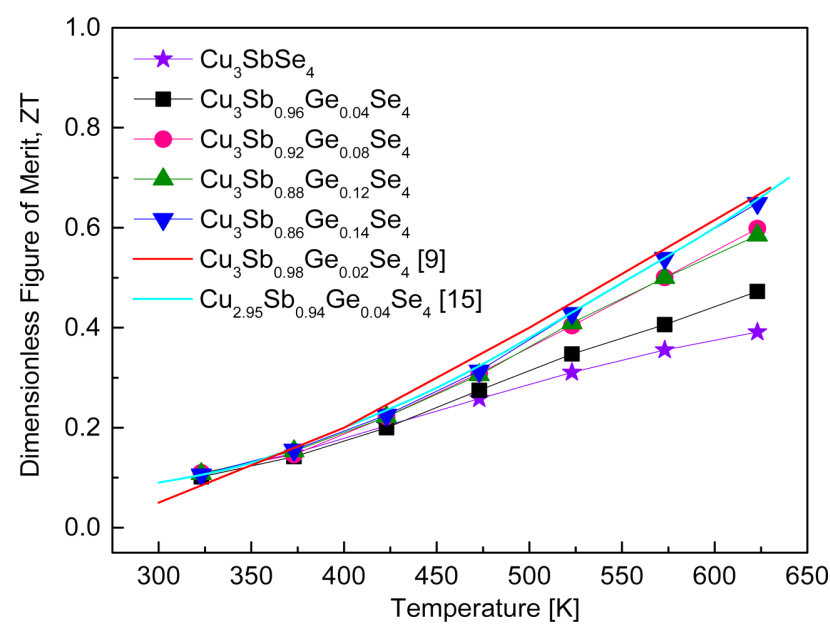

Fig. 10. Temperature dependence of thermoelectric figure of merit for $\mathrm{Cu}_{3} \mathrm{Sb}_{1-\mathrm{y}} \mathrm{Ge}_{\mathrm{y}} \mathrm{Se}_{4}$.

$\mathrm{K}$ with increasing Ge content at constant temperature.

Figure 10 presents the dimensionless figure of merit for $\mathrm{Cu}_{3} \mathrm{Sb}_{1-y} \mathrm{Ge}_{y} \mathrm{Se}_{4}$. The dimensionless figure of merit was evaluated using the relationship ZT $=\alpha^{2} \sigma \kappa^{-1} \mathrm{~T}$. ZT increased with increasing temperature because of the temperature dependences of the power factor and thermal conductivity. $\mathrm{Cu}_{3} \mathrm{SbSe}_{4}$ exhibited a maximum ZT of 0.39 at $623 \mathrm{~K}$, whereas the ZT was significantly improved by Ge doping. $\mathrm{Cu}_{3} \mathrm{Sb}_{0.86} \mathrm{Ge}_{0.14} \mathrm{Se}_{4}$ showed the highest ZT (0.65) at $623 \mathrm{~K}$. Although Ge doping increased the thermal conductivity, the ZT improvement arose from the remarkably increased power factor. Skoug et al. [9] reported a ZT of 0.68 at $630 \mathrm{~K}$ for $\mathrm{Cu}_{3} \mathrm{Sb}_{0.98} \mathrm{Ge}_{0.02} \mathrm{Se}_{4}$ prepared by melting at $1173 \mathrm{~K}$ for $12 \mathrm{~h}$ and annealing at $573 \mathrm{~K}$ for $48 \mathrm{~h}$ followed by HP. Chang et al. [15] obtained a ZT of 0.54 at $640 \mathrm{~K}$ for $\mathrm{Cu}_{2.95} \mathrm{SbSe}_{4}$ and 0.70 at $640 \mathrm{~K}$ for $\mathrm{Cu}_{2.95} \mathrm{Sb}_{0.96} \mathrm{Ge}_{0.04} \mathrm{Se}_{4}$ synthesized by melting at $1123 \mathrm{~K}$ for several hours, annealing at $653 \mathrm{~K}$ for $40 \mathrm{~h}$, and SPS.

In this study, solid-state synthesis via the MA-HP process was successful in preparing Ge-doped permingeatite compounds in a relatively short time (MA for $12 \mathrm{~h}$ ) without subsequent heat treatment. The MA-HP method was confirmed to be an economical and practical process that saved time and energy in the fabrication of homogenous Ge-doped permingeatite. The obtained thermoelectric performance was comparable to that of permingeatite produced by the melting process. 


\section{Conclusions}

Ge-doped permingeatites $\mathrm{Cu}_{3} \mathrm{Sb}_{1-y} \mathrm{Ge}_{y} \mathrm{Se}_{4}(y=0-0.14)$ were successfully prepared by MA and HP. The phase, microstructure, charge transport, and thermoelectric properties were examined with respect to the Ge content. A permingeatite phase with a tetragonal structure was formed in all samples, and the secondary phase of $\mathrm{Cu}_{2} \mathrm{GeSe}_{3}$ was detected when $y \geq 0.08$. Both undoped and Ge-doped specimens exhibited p-type characteristics, and the carrier (hole) concentration increased with increasing Ge content. $\mathrm{Cu}_{3} \mathrm{SbSe}_{4}$ showed non-degenerate semiconductor behavior, while the Ge-doped specimens were degenerate in nature. As the Ge content increased, the Seebeck coefficient decreased, while the electrical conductivity and power factor increased. However, the thermal conductivity increased because of the increased electronic thermal conductivity. As a result, $\mathrm{Cu}_{3} \mathrm{Sb}_{0.86} \mathrm{Ge}_{0.14} \mathrm{Se}_{4}$ achieved the maximum $\mathrm{ZT}$ of 0.65 at $623 \mathrm{~K}$, resulting from its low thermal conductivity of $0.89 \mathrm{~W} \cdot \mathrm{m}^{-1} \cdot \mathrm{K}^{-1}$ and maximized power factor of $0.93 \mathrm{~mW} \cdot \mathrm{m}^{-1} \cdot \mathrm{K}^{-2}$.

\section{Acknowledgment}

This study was supported by the Basic Science Research Capacity Enhancement Project (National Research Facilities and Equipment Center) through the Korea Basic Science Institute funded by the Ministry of Education (Grant No. 2019R1A6C1010047).

\section{REFERENCES}

1. K. Tyagi, B. Gahtori, S. Bathula, V. Toutam, S. Sharma, N. K. Singh, and A. Dhar, Appl. Phys. Lett. 105, 261902 (2014).

2. A. Kumar, P. Dhama, and P. Banerji, AIP Conf. Proc. 1832, 110050 (2016).

3. T. H. Zou, X. Y. Qin, D. Li, G. L. Sun, Y. C. Dou, Q. Q. Wang, B. J. Ren, J. Zhang, H. X. Xin, and Y. Y. Li, Appl. Phys. Lett. 104, 013904 (2014).
4. Y. Zhang, E. Skoug, J. Cain, V. Ozolin, D. Morelli, and C. Wolverton, Phys. Rev. B 85, 054306 (2012).

5. J. H. Wernick and K. E. Benson, J. Phys. Chem. Sol. 3, 157 (1957).

6. D. Zhang, J. Yang, Q. Jiang, Z. Zhou, X. Li, Y. Ren, J. Xin, A. Basit, X. He, W. Chu, and J. Hou, J. Alloys Compd. 724, 597 (2017).

7. G. Garcia, P. Palacios, A. Cabot, and P. Wahnon, Inorg. Chem. 27, 7321 (2018).

8. C. Yang, F. Huang, L. Wu, and K. Xu, J. Phys. D: Appl. Phys. 44, 295404 (2011).

9. E. Skoug, J. D. Cain, P. Majsztrik, M. Kirkham, E. L. Curzio, and D. T. Morelli, Sci. Adv. Mater. 3, 602 (2011).

10. P. M. Ortiz, S. L. Loredo, J. C. Alvarez, Y. P. Mendez, and J. A. Martinez, Mater. Res. Bull. 102, 418 (2018).

11. D. Zhao, D. Wu, and L. Bo, Energies 10, 1524 (2017).

12. Y. Li, X. Qin, D. Li, X. Li, Y. Liu, J. Zhang, C. Song, and H. Xin, RSC Adv. 5, 31399 (2015).

13. X. Y. Li, D. Li, H. X. Xin, J. Zhang, C. J. Song, and X. Y. Qin, J. Alloys Compd. 561, 105 (2013).

14. T. R. Wei, H. Wang, Z. M. Gibbs, C. F. Wu, G. J. Snyder, and J. F. Li, J. Mater. Chem. 2, 13527 (2014).

15. C. H. Chang, C. L. Chen, W. T. Chiu, and Y. Y. Chen, Mater. Lett. 186, 227 (2017).

16. G. E. Lee and I. H. Kim, Materials 14, 1116 (2021).

17. L. D. Gulay and M. Daszkiewicz, Hand. Phys. Chem. Rare Earths 41, 157 (2011).

18. J. W. Anthony, K. W. Bideaux, and M. C. Nichols, Handbook of Mineralogy, Vol. 1: Elements, Sulfides, Sulfosalts, p.1613, Mineral Data Publishing, Arizona, USA (2003).

19. H. Brooks, Adv. Electron. Electron. Phys. 7, 85 (1955).

20. D. Vashaee and A. Shakouri, Phys. Rev. Lett. 92, 106103 (2004).

21. Y. Yan, H. Wu, G. Wang, X. Lu, and X. Zhou, Energy Stor. Mater. 13, 127 (2018).

22. S. G. Kwak, J. H. Pi, G. E. Lee, and I. H. Kim, Korean J. Met. Mater. 58, 272 (2020).

23. B. Madavali and S. J. Hong, J. Electron. Mater. 45, 6059 (2016). 